\title{
Erratum to: Molecular simulation and experimental studies of the miscibility of chitosan/poly(ethylene oxide) blends
}

\author{
Natthida Rakkapao ${ }^{1}$ - Visit Vao-soongnern ${ }^{2}$
}

Published online: 16 November 2015

(C) Springer Science+Business Media Dordrecht 2015

Erratum to: J Polym Res (2014) 21:606

DOI 10.1007/s10965-014-0606-1

The author Dr. Natthida Rakkapao has informed us that since 2011 she is affiliated with the Faculty of Science and Industrial Technology, Prince of Songkla University, Suratthani Campus, 84000, Thailand. The paper was based on experimental work and analysis carried out at Suranaree Universty of Technology, whilst the manuscript was largely written at Prince of Songkla University, with assistance from the PSU publication clinic.

For correspondence, Dr Rakkapao's current e-mail address is natthida.r@psu.ac.th. 10.1007/s10965-014-0606-1.

Visit Vao-soongnern

visit@sut.ac.th

Natthida Rakkapao

natthida.r@psu.ac.th

1 Faculty of Science and Industrial Technology, Prince of Songkla University, Suratthani Campus, Suratthani 84000, Thailand

2 School of Chemistry, Institute of Science, Suranaree University of Technology, Ratchasima 30000, Thailand 